\title{
Enhanced Removal of Phenol from Aquatic Solution in a Schorl-catalyzed Fenton-like System by Acid-modified Schorl
}

\author{
Huan-Yan Xu, ${ }^{*}$ Murari Prasad, ${ }^{\dagger}$ and Peng Wang \\ College of Materials Science and Engineering, Harbin University of Science and Technology, Harbin 150040, China \\ ${ }^{*}$ E-mail:xhy7587@yahoo.com.cn \\ ${ }^{\dagger}$ Environmental Chemistry Division, Advanced Materials and Processing Research Institute (C.S.I.R.), Bhopal 462006, India \\ ${ }^{\sharp}$ School of Municipal and Environmental Engineering, Harbin Institute of Technology, Harbin 150090, China \\ Received October 11, 2009, Accepted January 15, 2010
}

\begin{abstract}
Schorl modified by $\mathrm{H}_{2} \mathrm{SO}_{4}$ has been successfully developed to enhance schorl-catalyzed Fenton-like reaction for removal of phenol in an aqueous solution. The phenol removal percentage can be increased from $4 \%$ to $100 \%$ by the system of modified schorl and $\mathrm{H}_{2} \mathrm{O}_{2}$. Batch experiments indicate that the percent increases in removal of phenol by increasing the dosage of catalyst, temperature and initial concentration of $\mathrm{H}_{2} \mathrm{O}_{2}$. The results of XRD, FT-IR and SEM suggest that no new phases are formed after removal of phenol by modified schorl. ICP-AES results reveal that more dissolution of iron results in higher catalytic oxidant activity in the system of modified schorl and $\mathrm{H}_{2} \mathrm{O}_{2}$. Besides minor adsorption, mineralcatalyzed Fenton-like reaction governs the process.
\end{abstract}

Key Words: Modified schorl, Phenol, Fenton-like reaction, Mechanism

\section{Introduction}

Phenol is a major water pollutant. Phenolic compounds are popularly used in the preparation of various organic products. ${ }^{1}$ Owing to their toxic effects, phenolic contaminants can damage sensitive cells and thus cause profound health and environmental problems. ${ }^{2}$ Various treatment techniques have been applied to remove or eliminate phenolic compounds from wastewaters, including chemical oxidation, ${ }^{3}$ solvent extraction, ${ }^{4-6}$ membrane techniques, ${ }^{6-8}$ adsorption, ${ }^{9,10}$ photodegradation, ${ }^{11}$ coagulation flocculation, ${ }^{12}$ biological process ${ }^{2,13}$ and so on. However, such technologies usually involve complicated procedures and are not economically viable.

Fenton's reagent [ $\mathrm{Fe}(\mathrm{II})+$ hydrogen peroxide], a widely used and studied catalytic treatment system, has been applied to treat various organic wastes. ${ }^{14,15}$ Hydroxyl radicals $(\bullet \mathrm{OH})$ is generated by the $\mathrm{Fe}(\mathrm{II})$-catalyzed decomposition of hydrogen peroxide $\left(\mathrm{H}_{2} \mathrm{O}_{2}\right) \cdot \cdot \mathrm{OH}$ is a very strong and non-specific oxidant which can oxidize almost all the organic compounds. However, the common drawback of Fenton's reaction is the generation of secondary pollutants, the ferric ions. Another separation unit is required in the downstream of the process in order to recover the ferric ions from the treated wastewaters. ${ }^{16}$ Heterogeneous catalysis at mineral surfaces, or geocatalysis, may be important in natural systems. ${ }^{17}$ Mineral-catalyzed Fenton-like system has been put forward to treat organic pollutants. ${ }^{18}$ The catalysts used in this Fenton-like system were natural iron-bearing earth materials, such as goethite, ${ }^{19-23}$ hematite, ${ }^{24-26}$ magnetite, ${ }^{24,27}$ ferrihydrite ${ }^{24,28}$ and so on. These iron-bearing minerals could effectively catalyze $\mathrm{H}_{2} \mathrm{O}_{2}$ to oxide organic pollutants. However, the decomposition rates of organic pollutants in some of these Fenton-like systems seemed to be slow, generally speaking, tens or hundreds of minutes required for organic pollutants' total decomposition. To accelerate the decomposition rate, ultrasonic, electrostatic field or UV irradiation was added to assist Fenton-like sys- tems. ${ }^{21,27,29}$ Schorl is a natural iron-bearing mineral, which has spontaneous 'electrostatic poles' on its surface at room temperature. ${ }^{30}$ Hereby, we supposed that it could be as an effective iron dosage source for Fenton-like system and the electrostatic field generated by schorl would reinforce Fenton-like reaction.

We have concluded that dyeing wastewater could be effectively discolored by schorl-catalyzed Fenton-like system. ${ }^{31,32}$ But, according to previous experimental results, the efficiency of removal of phenol in water was not good. Hence, in this study, the attention has been paid to enhance the phenol removal by schorl-catalyzed Fenton-like system. In order to attain higher phenol removal efficiency, schorl was modified. And, the effects of various parameters, such as temperature, contact time, modified schorl dosage, and initial $\mathrm{H}_{2} \mathrm{O}_{2}$ concentration, have been investigated and the kinetic equation for phenol removal was developed. Changes in schorl's crystal-chemical properties before and after modification and after phenol removal have been characterized using X-ray diffraction (XRD), Fourier transform infrared spectroscopy (FT-IR), and Scanning electron microscope (SEM). The concentration of total iron dissolved in the solution was measured by inductively coupling plasma-atomic emission spectra (ICP-AES).

\section{Experimental Section}

Schor sample collection. The schorl sample was collected from Chi-Feng, Inner-Mongolia, China. It was black in color. The mineral sample was sieved, and sample of $-2 \mu \mathrm{m}$ size range was used in the present studies. The physical properties and chemical compositions have been mentioned in previous work. ${ }^{31,32}$

Characterization. XRD was employed to identify mineral phases of schorl before and after treatment with phenol solution. Measurements were made on a D/MAX-3B instrument with $\mathrm{Cu} \mathrm{K} \alpha$ radiation $(\lambda=1.54050 \AA)$ at $30 \mathrm{~mA}$ and $35 \mathrm{kV}$. FT-IR (SP3-300 IR spectrometer) was used to confirm the presence of 
chemical groups in the schorl structure. Schorl samples were mixed with $300 \mathrm{mg}$ of spectroscopic grade $\mathrm{KBr}$ and ground in an agate mortar. Scanning Electron Microscope (JSM-5500) with a digital imaging process was utilized to observe the crystal morphology. The content of total iron dissolved in the solution was measured by ICP-AES (Optima 5300 DV, PerkinElmer).

Phenol removal experiment. A stock solution containing phenol (1000 mg/L each) was prepared from an analytical-grade phenol reagent using doubly distilled water, subsequently diluted to the required concentrations for the experimental work. The $\mathrm{pH}$ was adjusted by addition of sodium hydroxide and nitric acid to the phenol solutions. The oxidant used was hydrogen peroxide $(30 \%, \mathrm{w} / \mathrm{w})$. Then, schorl mineral samples were added into $100 \mathrm{~mL}$ of solutions of required concentrations of phenol in a conical flask. After sealing, the conical flasks were placed in a constant-temperature water-bathing retort at temperatures and contact times. The suspensions were then filtered through a filter paper. The filtrates were analyzed for their phenol concentrations using a 752-type ultraviolet-visible spectrophotometer by 4-AAP spectrophotometric method. Blank experiments were carried out before all tests with the same experimental procedures in order to check the extent of phenol sorption by the glass flasks. The reproducibility tests of the results were done for different experimental conditions by random tests.

\section{Results and Discussion}

Schorl modification. Phenol could not be effectively removed by the catalytic oxidation system of raw schorl and $\mathrm{H}_{2} \mathrm{O}_{2}$ (only $4 \%$ removal) (Figure 1), so it was modified to yield higher removal percentage. As discussed in our previous studies, ${ }^{31,32}$ the contents of iron ions dissolved in solution played an important role in improving the catalytic activity of the schorl-catalyzed Fenton-like system. When more Fe ion was dissolved in the solution from schorl catalyst, $\mathrm{H}_{2} \mathrm{O}_{2}$ could be catalyzed to generate more $\mathrm{OH}$ radicals, resulting in a faster reaction. Therefore, two modifying agents; $\mathrm{A}\left(\mathrm{H}_{2} \mathrm{SO}_{4}\right)$ and $\mathrm{B}\left(\mathrm{FeSO}_{4}\right)$ were used. Raw schorl was respectively infused in the modifying agent solution of $6 \mathrm{~mol} / \mathrm{L}$ for $12 \mathrm{~h}$, then, dried at the temperature of $150{ }^{\circ} \mathrm{C}$. In order to identify whether it was modified schorl or modifying agent which played a major role in the removal of phenol, comparative investigations were carried out under similar experimental conditions. For $\mathrm{H}_{2} \mathrm{O}_{2} /$ schorl modified by $\mathrm{FeSO}_{4}$ system, though phenol can be removed effectively (approximately $100 \%$ removal), it is the modifying agent $\mathrm{FeSO}_{4}$ that plays the major role in the phenol removal (Figure 1). $\mathrm{Fe}^{2+}$ from $\mathrm{FeSO}_{4}$ catalyzes the decomposition of $\mathrm{H}_{2} \mathrm{O}_{2}$ to produce highly reactive $\cdot \mathrm{OH}$, which oxidized phenol. $\mathrm{FeSO}_{4} / \mathrm{H}_{2} \mathrm{O}_{2}$ is a typical Fenton's reagent used widely. ${ }^{33,34}$ For $\mathrm{H}_{2} \mathrm{O}_{2}$ /schorl modified by $\mathrm{H}_{2} \mathrm{SO}_{4}$ system, phenol can also be removed effectively with a maximum of $100 \%$ removal (Figure 1 ). Because $\mathrm{H}_{2} \mathrm{O}_{2}$ can not be catalyzed by $\mathrm{H}_{2} \mathrm{SO}_{4}$ to produce $\cdot \mathrm{OH}$, it is concluded that schorl modified by $\mathrm{H}_{2} \mathrm{SO}_{4}$ governs the $\bullet \mathrm{OH}$ generation process. So, it was selected preferably in this study.

Phenol removal by modified schorl and $\mathrm{H}_{2} \mathrm{O}_{2}$. The effect of $\mathrm{H}_{2} \mathrm{O}_{2}$ concentration on phenol removal was shown in Figure 2. The data clearly indicate that the phenol removal percentage increases with an increase in $\mathrm{H}_{2} \mathrm{O}_{2}$ concentration which suggests

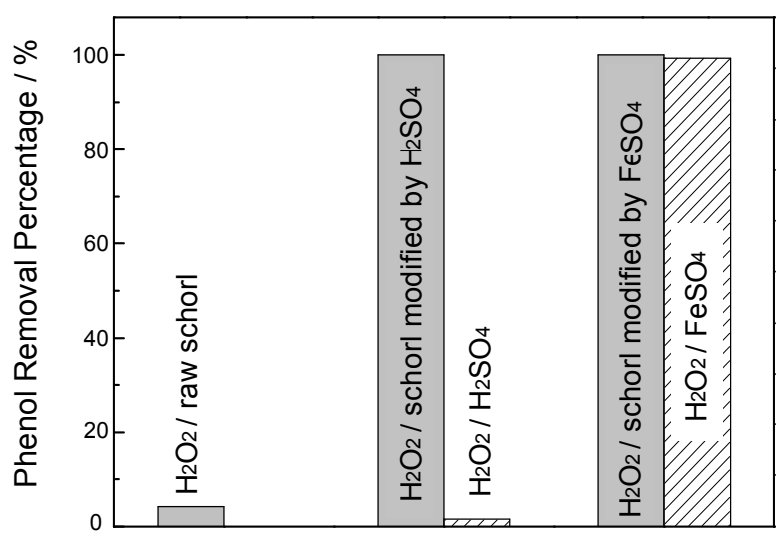

Figure 1. Comparative analysis on the phenol removal by different catalytic oxidation systems.

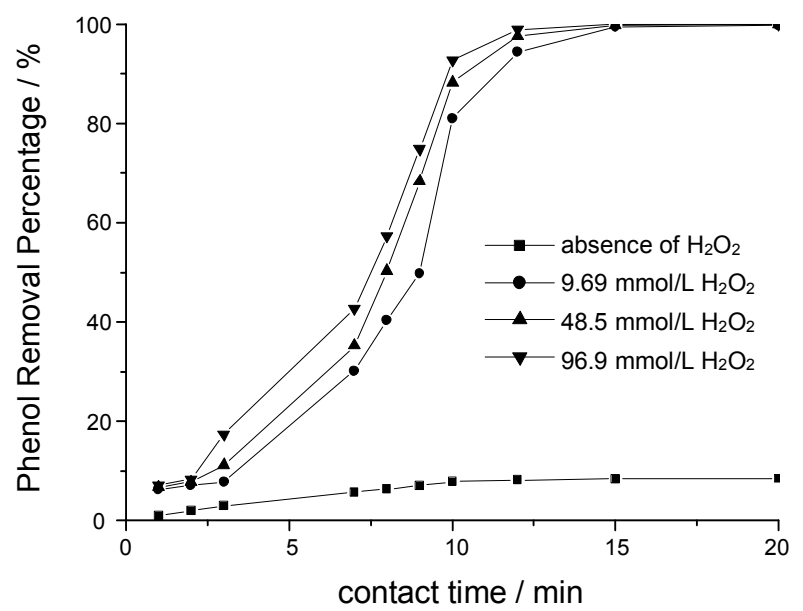

Figure 2. Phenol removal at different $\mathrm{H}_{2} \mathrm{O}_{2}$ concentration at $\mathrm{T}=80{ }^{\circ} \mathrm{C}$, $\mathrm{pH}=6$, initial phenol concentration $=100 \mathrm{mg} / \mathrm{L}$ and catalyst dosage $=$ $10 \mathrm{~g} / \mathrm{L}$.

about more generation of $\mathrm{OH}$ radicals at higher $\mathrm{H}_{2} \mathrm{O}_{2}$ concentration. ${ }^{31}$ So, the increase in $\mathrm{H}_{2} \mathrm{O}_{2}$ concentration leads to higher system reactivity. Above $90 \%$ removal of phenol occurs in the first $9 \mathrm{~min}$, which reveals that the rate of phenol removal is very rapid. Otherwise, in the absence of $\mathrm{H}_{2} \mathrm{O}_{2}$, only less than $10 \%$ of phenol can be removed, which is resulted by adsorption of schorl. Only when both the oxidant and solid catalyst are present, phenol can be removed significantly, due to the mineral-catalyzed Fenton-like reaction. Hereby, it can be presumed that the catalytic decomposition effect is a main factor for phenol removal and adsorption effect is a minor one. Similar result has been reported previously. ${ }^{31,32}$ The existence of alkali group ${ }^{35}$ and electrostatic field ${ }^{30}$ on the surface of schorl may be contributed to its adsorption properties. Figure 3 shows the effect of modified schorl dosage on phenol removal. It indicates that reactivity of the system increases with an increase in catalyst dosage, which may be attributed to more active $\mathrm{Fe}$ sites on the catalyst surface for accelerating the decomposition of $\mathrm{H}_{2} \mathrm{O}_{2}$ (heterogeneous catalysis) and more $\mathrm{Fe}$ ion leaching in the solution leading to an increase in the number of $\mathrm{OH}$ radicals (homogeneous catalysis). ${ }^{36}$ On the other hand, in absence of modified schorl cata- 


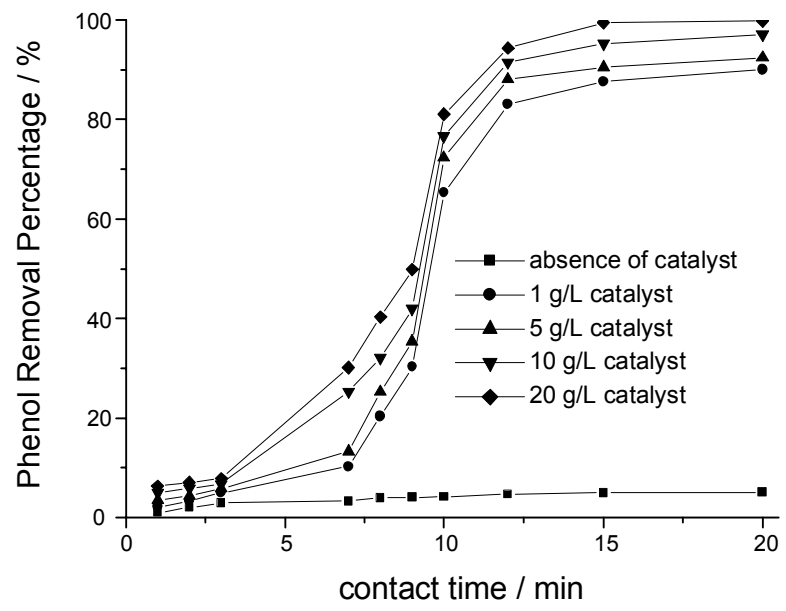

Figure 3. Phenol removal at different catalyst dosage at $\mathrm{T}=80^{\circ} \mathrm{C}, \mathrm{pH}=$ 6 , initial phenol concentration $=100 \mathrm{mg} / \mathrm{L}$ and initial $\mathrm{H}_{2} \mathrm{O}_{2}$ concentration $=96.9 \mathrm{mmol} / \mathrm{L}$.

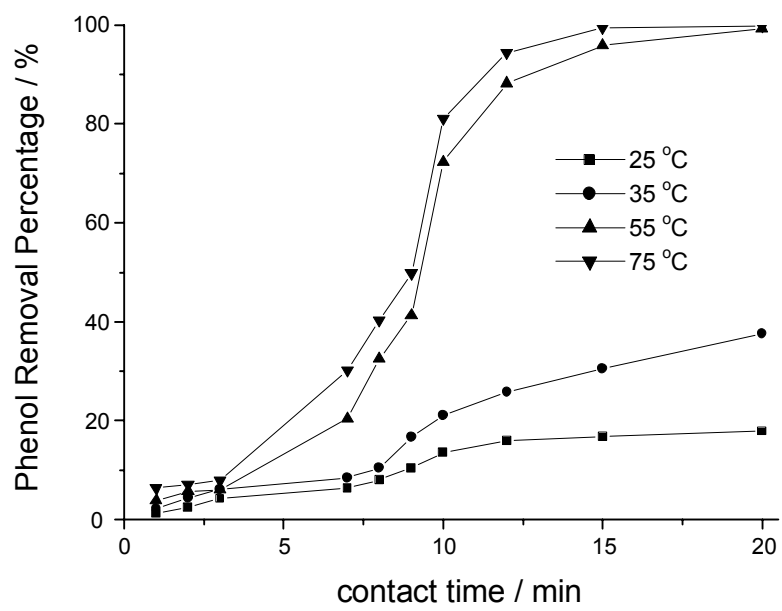

Figure 4. Phenol removal at different ambient temperature at $\mathrm{pH}=6$, catalyst dosage $=10 \mathrm{~g} / \mathrm{L}$, initial phenol concentration $=100 \mathrm{mg} / \mathrm{L}$ and initial $\mathrm{H}_{2} \mathrm{O}_{2}$ concentration $=96.9 \mathrm{mmol} / \mathrm{L}$.

lyst, $\mathrm{H}_{2} \mathrm{O}_{2}$ can not be catalyzed to oxidize phenol, so the phenol removal percentage is approximately zero. The effect of reaction temperature on the phenol removal was studied (Figure 4). The reactivity of the system increases by increasing reaction temperature. It may be due to faster catalysis of $\mathrm{H}_{2} \mathrm{O}_{2}$ at a higher temperature resulting in the increase in the number of $\mathrm{OH}$ radicals. Another plausible explanation may be that a higher temperature could provide more energy for the reactant molecules to overcome reaction activation energy as described elsewhere. ${ }^{36}$ Subsequently, the results from the orthogonal array $\left[\mathrm{L}_{16}(5 \times 4)\right]$ analysis indicate that the optimum conditions for the phenol removal can be summarized as follows: the initial $\mathrm{H}_{2} \mathrm{O}_{2}$ concentration, $96.9 \mathrm{mmol} / \mathrm{L}$; the contact time, $10 \mathrm{~min}$; the modified schorl dosage, $5 \mathrm{~g} / \mathrm{L}$; the temperature, $70{ }^{\circ} \mathrm{C}$; and the solution $\mathrm{pH}, 6$. Under the optimum condition, the phenol removal percentage may be achieved $100 \%$. The modified Fentonlike system appears to be a promising method for treating organic pollutant wastewater when compared with homogeneous

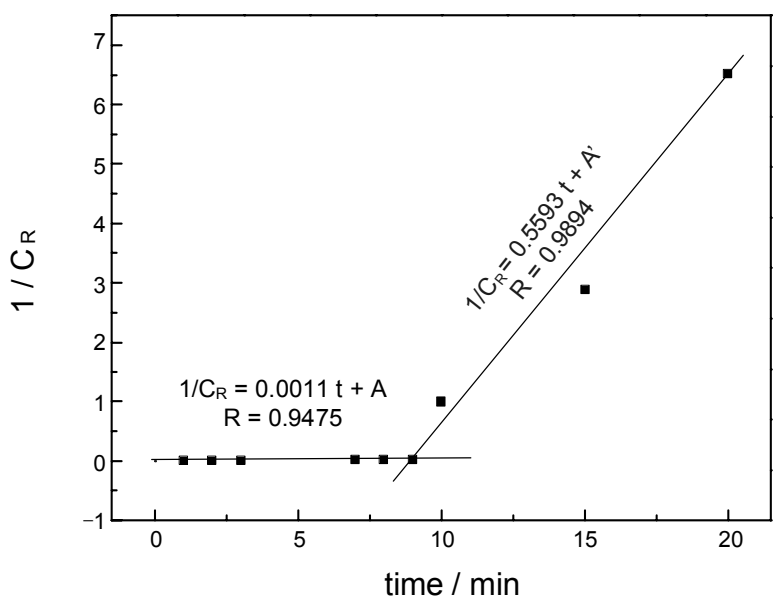

Figure 5. Kinetic cures for the phenol removal.

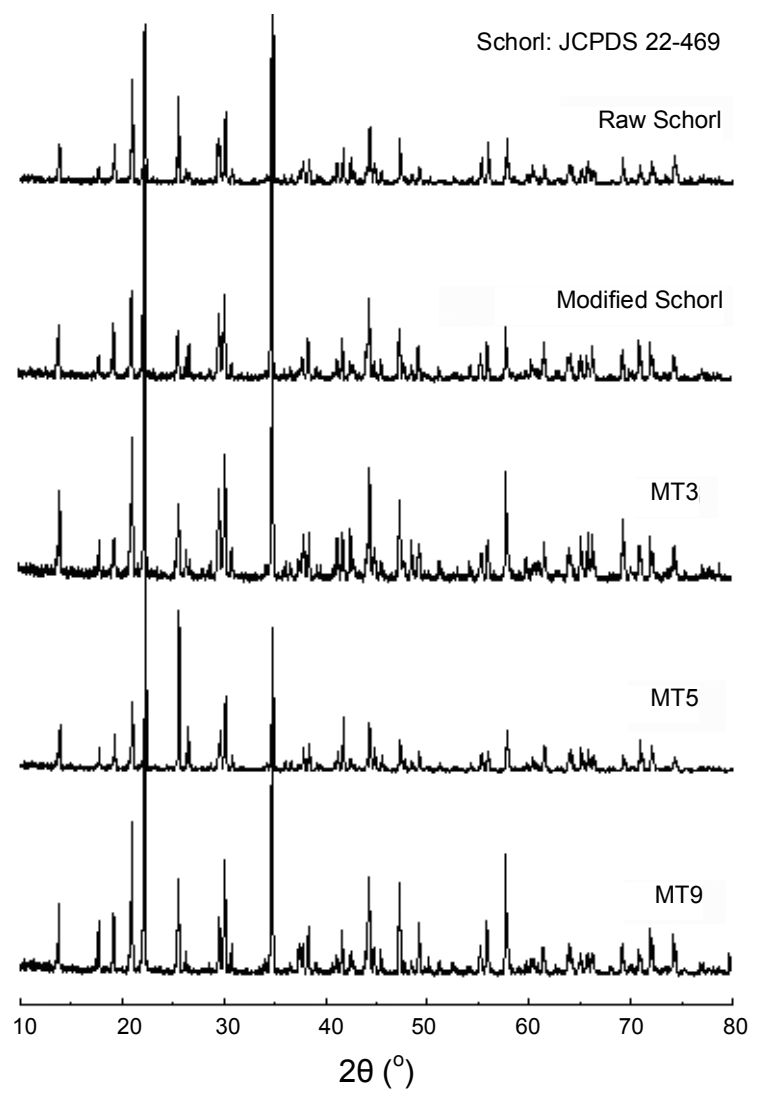

Figure 6. XRD patterns of schorl, modified schorl and samples after phenol removal. MT3, MT5, and MT9 are the symbols for the samples after phenol removal under different experiments, samples were selected at random.

Fenton's reagent due to its unique advantages of easy separation of heterogeneous catalyst from the treated wastewater, high catalytic reactivity at neutral $\mathrm{pH}$ range and lower $\mathrm{H}_{2} \mathrm{O}_{2}$ concentration.

Taking the reciprocal of the concentration of phenol in solution after removal $\left(1 / \mathrm{C}_{\mathrm{R}}\right)$ as the $\mathrm{Y}$-axis and contact time $(t)$ as the $\mathrm{X}$-axis, Figure 5 is obtained under the experimental condi- 


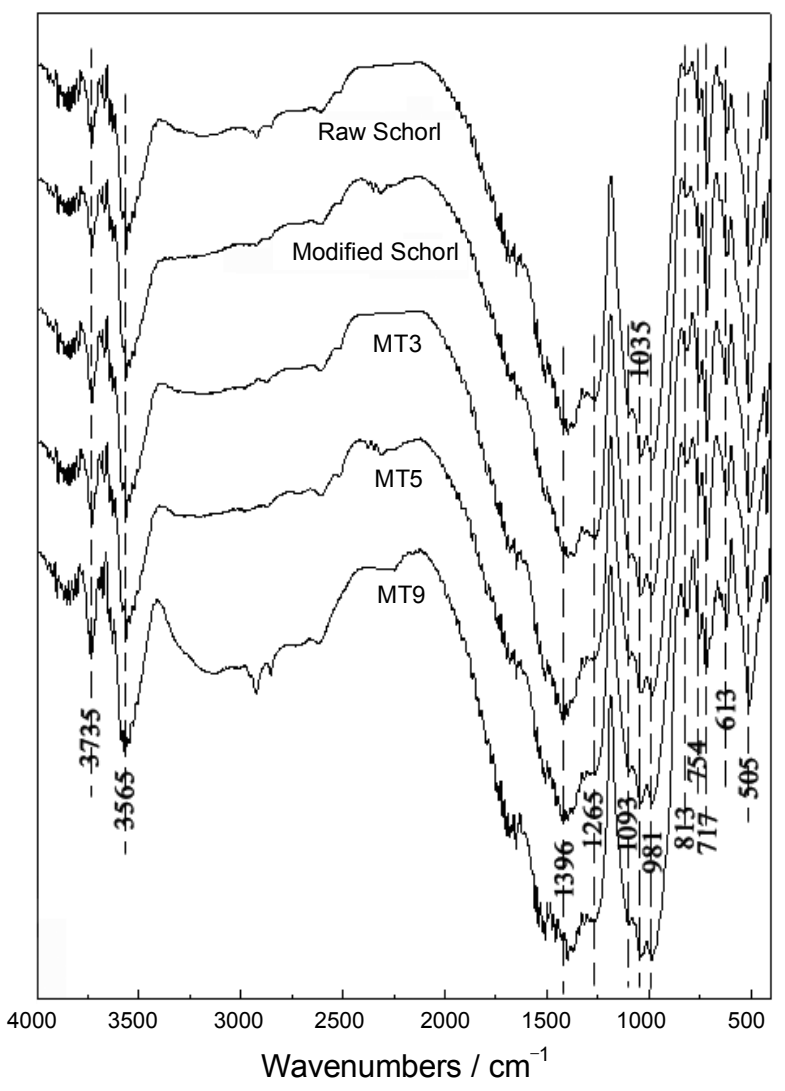

Figure 7. FT-IR spectra of schorl, modified schorl and samples after phenol removal. MT3, MT5 and MT9 are the symbols for the samples after phenol removal under different experiments, samples were selected at random.

tions: $\mathrm{pH}, 6$; dosage of modified schorl, $10 \mathrm{~g} / \mathrm{L}$; temperature, $80^{\circ} \mathrm{C}$; the initial phenol concentration, $100 \mathrm{mg} / \mathrm{L}$; and the initial $\mathrm{H}_{2} \mathrm{O}_{2}$ concentration, $96.9 \mathrm{mmol} / \mathrm{L}$. It is observed from Fig. 5 that there exist two stages from the point of view of kinetics. At the earlier stage $(0 \leq t \leq 9 \mathrm{~min})$, the removal reaction process follows that of a second order kinetic equation with slower reaction rate, and the kinetic equation can be described as follows:

$$
1 / \mathrm{C}_{\mathrm{R}}=0.0011 t+\mathrm{A} \quad[\mathrm{R}=0.9475]
$$

Reaction rate constant, $k=0.0011 \mathrm{~L} \cdot \mathrm{mg}^{-1} \cdot \mathrm{min}^{-1}$ and half life, $t_{1 / 2}=9.091 \mathrm{~min}$. At latter stage $(t \geq 9 \mathrm{~min})$, it also follows that of a second order kinetic equation, but, with faster reaction rate, and the kinetic equation can be described as follows:

$$
1 / \mathrm{C}_{\mathrm{R}}=0.5593 t+\mathrm{A}^{\prime} \quad[\mathrm{R}=0.9894]
$$

Reaction rate constant, $k=0.5593 \mathrm{~L} \cdot \mathrm{mg}^{-1} \cdot \mathrm{min}^{-1}$ and half life, $t_{1 / 2}=0.0179 \mathrm{~min}$.

Mechanism. A further investigation using XRD, FT-IR and SEM to characterize the schorl samples before and after modification and phenol removal shows the following results:

(i) No new phase formation in the schorl samples was detected by XRD after modification and phenol removal. For the raw sample, except for schorl, there exist no other mineral phases in the sample (matching JCPDS 22-469). For the samples after
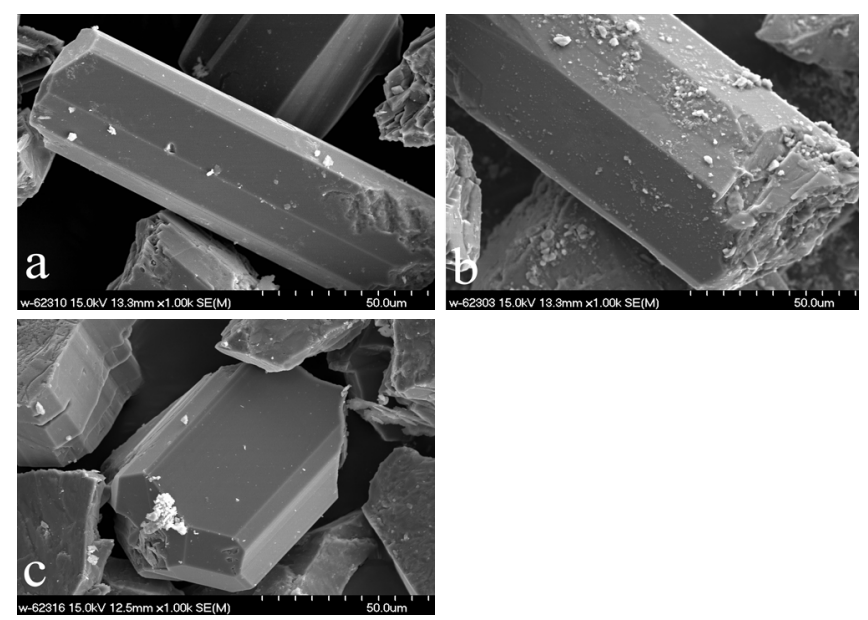

Figure 8. Secondary electron images of SEM for (a) schorl, (b) modified schorl and (c) samples after phenol removal.

modification and phenol removal, their XRD peaks all belong to those of schorl and no new peak appears (Figure 6);

(ii) No new absorption band was detected by FT-IR and all the absorption bands are assigned to schorl samples (Figure 7). In the $\mathrm{OH}$ stretching region $\left(\geq 3300 \mathrm{~cm}^{-1}\right)$, it is easy to distinguish the inner hydroxyl group, with low-intensity band at high wavenumbers $\left(3735 \mathrm{~cm}^{-1}\right)$, from the outer one which produce broad high-intensity low-wavenumber band $\left(3565 \mathrm{~cm}^{-1}\right){ }^{37}$ The bands at 1396 and $1265 \mathrm{~cm}^{-1}$ are assigned to the stretching vibrations of the $\mathrm{BO}_{3}$ group. ${ }^{38}$ The bands at 1093,1035 and $981 \mathrm{~cm}^{-1}$ are assigned to the $\mathrm{Si}_{6} \mathrm{O}_{18}$ stretching vibrations. ${ }^{38}$ In the range 800 $350 \mathrm{~cm}^{-1}$, complicated bands assigned to many vibration modes are observed. ${ }^{37}$ Except for the bands of schorl, no new band and distinct difference appear in the FTIR spectra;

(iii) No change in the schorl crystal morphology was observed by SEM (Figure 8). The morphological observations reveal that the shape of samples is hexagonal cylinders and irregular granules, with crystal sizes ranging from 1 to $60 \mu \mathrm{m}$. For the sample after modification (Figure 8 (b)), there are some deposits on the schorl surface, which may be due to the formation of $\mathrm{H}_{2} \mathrm{SO}_{4}$ crystal during the modification process.

It may be interpreted by these results that the samples still have the typical trigonal structure and crystal morphology of schorl and there are not any new phases formed after modification and removal. However, phenol can be better removed by the catalytic oxidant system of modified schorl and $\mathrm{H}_{2} \mathrm{O}_{2}$ than that of raw schorl and $\mathrm{H}_{2} \mathrm{O}_{2}$. This behavior may be explained by more dissolution of iron ions in the system of modified schorl and $\mathrm{H}_{2} \mathrm{O}_{2}$ as detected by ICP-AES. The total concentration of iron ion dissolved in solution is $0.149 \mathrm{mmol} / \mathrm{L}$ after one minute and is maintained near $0.143-0.161 \mathrm{mmol} / \mathrm{L}$ during the reaction process, in the system of modified schorl and $\mathrm{H}_{2} \mathrm{O}_{2}$ under the experimental conditions (catalyst dosage, $5 \mathrm{~g} / \mathrm{L}$; initial $\mathrm{H}_{2} \mathrm{O}_{2}$ concentratio, $24.23 \mathrm{mmol} / \mathrm{L}$; $\mathrm{pH}, 6$; ambient temperature, $80{ }^{\circ} \mathrm{C}$ ). However, the total concentration of iron ion is only $1.7 \times 10^{-3}$ $\mathrm{mmol} / \mathrm{L}$ under similar conditions in the system of raw schorl and $\mathrm{H}_{2} \mathrm{O}_{2}$. Three processes occur in mineral-catalyzed Fentonlike system, the first is the adsorption of organic pollutants on the surface of mineral catalyst; the second is the oxidation of organic 
pollutants by heterogeneous Fenton reaction being catalyzed by active Fe sites on the surface of catalyst; and the last process is the oxidation of organic pollutants by homogeneous Fenton reaction being catalyzed by $\mathrm{Fe}^{2+} / \mathrm{Fe}^{3+}$ leaching in the solution. ${ }^{31,32,36}$ Thus, more dissolved iron ions in solution make higher catalytic oxidant activity in the system of modified schorl and $\mathrm{H}_{2} \mathrm{O}_{2}$. At the same time, the results of XRD, FT-IR and SEM after phenol removal rule out the possibility of formation of new solid phases during phenol removal. Though the adsorbed substance is not detected due to lesser contribution, adsorption does exist in the process of phenol removal as discussed above.

\section{Conclusion}

Phenol in an aqueous solution could be effectively removed by schorl-catalyzed Fenton-like system enhanced by $\mathrm{H}_{2} \mathrm{SO}_{4}$ modified schorl. A number of batch experiments under various conditions for phenol removal strongly indicated that higher removal percentage may be attained by increasing catalyst dosage, temperature and initial $\mathrm{H}_{2} \mathrm{O}_{2}$ concentration. The optimum conditions for the phenol removal could be described as follows: the initial $\mathrm{H}_{2} \mathrm{O}_{2}$ concentration was $96.9 \mathrm{mmol} / \mathrm{L}$, the contact time was $10 \mathrm{~min}$, the modified schorl dosage was $5 \mathrm{~g} / \mathrm{L}$, the temperature was $70{ }^{\circ} \mathrm{C}$ and the solution $\mathrm{pH}$ was 6 . Under the optimum condition, $100 \%$ phenol removal may be achieved. The phenol removal reaction mechanism involved adsorption and mineral-catalyzed Fenton-like reaction. More iron ions dissolved in solution made higher homogeneous catalytic activity in the system of $\mathrm{H}_{2} \mathrm{SO}_{4}$ modified schorl and $\mathrm{H}_{2} \mathrm{O}_{2}$.

Acknowledgments. This work was supported by a grant from Scientific Foundation of Heilongjiang Office of Education (no. 11531035) and Natural Science Foundation of Heilongjiang Province, China (no. E200906).

\section{References}

1. Asok, A.; Anjali, P. Sep. Purif. Technol. 2006, 50, 256.

2. Tziotzios, G.; Teliou, M.; Kaltsouni, V.; Lyberatos, G.; Vayenas, D.V. Biochem. Eng. J. 2005, $26,65$.

3. Liou, R. M.; Chen, S. H.; Hung, M. Y.; Hsu, C. S.; Lai, J. Y. Chemosphere 2005, 59, 117.

4. Yang, C. F.; Qian, Y.; Zhang, L. J.; Feng, J. Z. Chem. Eng. J. 2006, $117,179$.

5. Li, Z.; Wu, M. H.; Jiao, Z.; Bao, B. R.; Lu, S. L. J. Hazard. Mater. 2004, B114, 111.

6. Wojciech, K.; Andrzej, W.; Wlodzimierz, R.; Tadeusz, P.; Wiest- aw, C.; Izabela, O. Desalination 2004, 163, 287.

7. Tarakranjan, G.; Narayan, C. P.; Basudam, A.J. Membr. Sci. 2003, $217,43$.

8. El-Kosasy, A. M.; Riad, S. M.; Abd El-Fattah, L. E.; Abd El-Kader, A. S. Water Res. 2003, 37, 1769.

9. Ahmaruzzaman, M.; Sharma, D. K. J. Colloid Interface Sci. 2005, 287,14

10. Bekkouche, S.; Bouhelassa, M.; Hadj, S. N.; Meghlaoui, F. Z. Desalination 2004, 166, 355 .

11. Will, I. B. S.; Moraes, J. E. F.; Teixeira, A. C. S. C.; Guardani, R.; Nascimento, C. A. O. Sep. Purif. Technol. 2005, 34, 51.

12. Tomaszewska, M.; Mozia, S.; Morawski, W. Desalination 2004, 162,79

13. Hsien, T. Y.; Lin, Y. H. Biochem. Eng. J. 2005, 27, 95.

14. Malik, P. K. J. Phys. Chem. A 2004, 108, 2675.

15. Duesterberg, C. K.; Waite, T. D. Environ. Sci. Technol. 2006, 40, 4189.

16. Leung, Y. F. Ph. D. Thesis, The Hong Kong University of Science and Technology, HongKong, 2005.

17. Schoonen, M. A. A.; Xu, Y.; Strongin, D. R. J. Geochem. Explor. 1998, 62, 201.

18. Kwan, W.; Voelker, B. Environ. Sci. Technol. 2003, 37, 1150.

19. Andreozzi, R.; Caprio, V.; Marotta, R. Water Res. 2002, 36, 2761.

20. Andreozzi, R.; D’Apuzzo, A.; Marotta, R. Water Res. 2002, 36, 4691.

21. He, J.; Ma, W. H.; Zhao, J. C.; Yu, J. C. Appl. Catal. B: Environ. 2002, 39, 211.

22. Chou, S. S.; Huang, C. P.; Huang, Y. H. Environ. Sci. Technol. 2001, 35, 1247.

23. Lu, M. C. Chemosphere 1999, 40, 125.

24. Teel, A. L.; Warberg, C. R.; Atkinson, D. A.; Wattsi, R. J. Water Res. 2001, 35, 977.

25. Huang, H. H.; Lu, M. C.; Chen, J. N. Water Res. 2001, 35, 2291.

26. Lin, S. S.; Gurol, M. D. Environ. Sci. Technol. 1998, 32, 1417.

27. Kwan, W.; Voelker, B. Environ. Sci. Technol. 2004, 38, 3425.

28. Kwan, W.; Voelker, B. Environ. Sci. Technol. 2002, 36, 1467.

29. Muruganandham, M.; Yang, J. S.; Wu, J. J. Ind. Eng. Chem. Res. 2007, 46, 691.

30. Nakamura, T.; Kubo, T. Ferroelectr. 1992, 137, 13.

31. Xu, H. Y.; Prasad, M.; Liu, Y.J. Hazard. Mater. 2009, $165,1186$.

32. Xu, H. Y.; Prasad, M.; He, X. L.; Shan, L. W.; Qi, S. Y. China Ser. E-Tech. Sci. 2009, 52, 3054.

33. Kazmi, A. A.; Thul, R. J. Environ. Sci. Eng. 2007, 49, 189.

34. Chang, C. Y.; Wang, C. C.; Chang, D. J.; Chang J. S. Water Sci. Technol. 2003, 47, 179 .

35. Jiang, K.; Sun, T. H.; Sun, L. N.; Li, H. B. J. Environ. Sci. 2006, 18,1221

36. Feng, J. Y.; Hu, X. J.; Yue, P. L. Environ. Sci. Technol. 2004, 38 , 269.

37. Robert, J. L.; Fuchs, Y.; Gourdant, J. P. Phys. Chem. Min. 1996, 23, 309.

38. Reddy, B. J.; Frost, R. L.; Martens, W. N.; Wain, D. L.; Kloprogge, J. T. Vib. Spectrosc. 2007, 44, 42. 